\title{
Asymmetrical international attitudes
}

\author{
JAN PIETER VAN OUDENHOVEN, ${ }^{1 *}$ \\ FRANÇOISE ASKEVIS-LEHERPEUX, ${ }^{2}$ \\ BETTINA HANNOVER, ${ }^{3}$ RENSKE JAARSMA ${ }^{1}$ \\ AND BENOÎT DARDENNE, ${ }^{4}$ \\ ${ }^{1}$ University of Groningen, The Netharlands \\ ${ }^{2}$ Université René Descartes-Paris 5, France \\ ${ }^{3}$ Universität Dortmund, Germany \\ ${ }^{4}$ Université de Liège, Belgium
}

\section{Abstract}

In general, attitudes towards nations have a fair amount of reciprocity: nations either like each other, are relatively indifferent to each other, or dislike each other. Sometimes, however, international attitudes are asymmetrical. In this study, we use social identity theory in order to explain asymmetrical attitudes. Parting from social identity theory, asymmetrical attitudes can be predicted to occur most likely between countries that are linguistically either similar or closely related, but differ in size. Europe, more than any other continent, offers a rich variety of nations which represent natural conditions for our study, such as size and degree of linguistic similarity. In order to test hypotheses derived from social identity theory, we asked respondents $(N=405)$ from (Dutch- and French-speaking) Belgium, France, Germany, and The Netherlands to fill out a questionnaire on three large nations (Germany, Great Britain, France) and three smaller ones (The Netherlands, Belgium, and Denmark). Results strongly supported hypotheses and confirm that a social identity approach may help to better understand international attitudes. Copyright (C) 2002 John Wiley \& Sons, Ltd.

\section{INTRODUCTION}

In accordance with both intuitive thoughts and cognitive balance models, one would expect that, in general, attitudes between nations have a fair amount of reciprocity: nations like each other, nations are relatively indifferent to each other, or nations dislike or even hate each other. Sometimes, however, we find asymmetrical international attitudes, especially between small and large nations, which differ not only according to the combined criteria of size of population and geographical size, but also in terms of political power. For example, the Germans appear to be more positive about the Dutch than the other way around (Van Oudenhoven, 2001), the French are more positive about the Portuguese

*Correspondence to: Jan Pieter van Oudenhoven, Department of Social Psychology, University of Groningen, Grote Kruisstraat 2/1, 9712 TS groningen, The Netherlands. E-mail: j.p.l.m.van.oudenhoven@ppsw.rug.nl 
than vice versa (Askevis-Leherpeux \& Bendano, presentation at the meeting 'Images réciproques France-Portugal', France, 1992), and Poles, Czechs, Bulgarians, and Belorussians rate Russians lower on morality than they are rated by Russians (Phalet \& Poppe, 1997).

In the present study we will apply social identity theory to the context of international relations. This is not a new approach. National and ethnic identities formed the ground where Tajfel began his theorising (Capozza \& Brown, 2000; Fiske 2000). We postulate that asymmetrical attitudes are to be found between small and large nations, in particular when they have the same or a closely related language, which is one of the important characteristics that forms a nation (Edwards, 1986).

\section{THEORETICAL BACKGROUND}

At first sight, three theories seem to be relevant to the domain of international attitudes: the similarityattraction hypothesis, the contact hypothesis, and social identity theory. According to the similarityattraction hypothesis (Baron \& Byrne, 2000; Byrne, 1971; Newcomb, 1961), which is more of a robust empirical datum than a theory, similarity leads to attraction. We like other individuals or groups who with respect to attitudes, values, and many other variables are seen to be similar to us or our group. The similarity-attraction hypothesis may explain why - in general-there are symmetrical relations, because attraction is linearly related to similarity. The theory cannot, however, offer an explanation for asymmetrical attitudes. It may not explain, for instance, why asymmetrical attitudes are found between nations that share a language or have closely related languages.

The basic assumption of the contact hypothesis (Allport, 1954) is that the behaviour and attitudes of people in relation to a social category whom they dislike become more positive after direct interpersonal contact, provided some conditions are met (Pettigrew, 1997; Sigelman \& Welch, 1993). A-somewhat implicit-assumption of the contact hypothesis is that lack of knowledge of each other leads to the perception of dissimilarity. Therefore, the more mutual contacts groups have, the more they know about each other, the more similar they are seen, the more positive attitudes they have in relation to each other (Rokeach, 1960). Thus, neither the contact hypothesis, being based on cognitive balance theories, is able to explain asymmetrical relations.

Social identity theory (Tajfel, 1978; Tajfel \& Turner, 1979) assumes that people strive to maintain or achieve a positive social identity, that evaluation of their own group occurs via social comparison with other groups, and that a positive social identity is based on a positive outcome of those comparisons. In order to obtain positive outcomes individuals look for positive distinctiveness and consequently tend to favour their own group and to denigrate other groups. By applying social identity theory to the domain of international attitudes we are able to explain the phenomenon of asymmetrical attitudes. In particular, from the just mentioned assumptions we can predict asymmetrical attitudes to exist primarily between countries of unequal size. Inhabitants of small nations have more trouble maintaining or creating a positive social identity as compared to inhabitants of larger nations. In social comparisons, inhabitants of smaller countries generally learn that their country has less political power, produces fewer top musicians and novelists, receives less international attention and media coverage, and that their politicians are generally less well known internationally. In order to maintain or enhance their social identity, they must view themselves more favourably and denigrate the larger nations.

Negative attitudes towards larger nations may, however, also be caused by real conflicts of interests resulting in the smaller countries having a higher level of frustration, as realistic group conflict theory (Campbell, 1965; Sherif, 1966) would contend. Real conflicts over resources or dominance may result in a perception of threat which in turn causes attribution of negative characteristics to the threatening group to explain the experienced threat (Bar-Tal, 1997). Probably the two processes-denigration to 
enhance social identity, and denigration as an inimical reaction to real conflicts - work together and reinforce each other. Members of larger nations, on the other hand, have no such reason to denigrate smaller nations since their identity is not threatened by comparison to smaller nations. Moreover, they have experienced that their country has been more capable of solving international disputes to their own advantage. Members of larger nations will, therefore, not show such a bias. Both on the basis of social identity theory and realistic group conflict theory we formulate the following hypothesis: While members of large nations do not evaluate larger ones as more sympathetic than smaller nations, members of smaller nations will evaluate smaller ones as more sympathetic than larger nations (Hypothesis 1).

Admittedly, differences in evaluation might reflect real differences in friendliness between small and larger nations. Larger nations may actually be more frustrating when they use their power to force smaller countries to comply with their wishes. Naturally such real differences in friendliness should lead to less positive ratings of larger nations, but there is no logical reason why they should lead to enhanced self-judgements by smaller nations. Such an extra positivity bias cannot be predicted on the basis of realistic conflict theory, but would be expected on the basis of social identity theory. Thus, whereas realistic conflict theory would not predict differences between smaller nations' self-ratings and their ratings of other small nations, social identity theory would predict enhanced self-ratings by smaller nations. Therefore, a strict test of social identity theory offers the following prediction: Members of small nations will judge their own nation as more sympathetic than they judge other small nations; by contrast, large nations will not show this kind of favouritism (Hypothesis 2).

An especially interesting case is presented when nations differ in size but share a language. The more common features two groups have, the more salient is one group's superiority to the other one. From this assumption one could directly infer the prediction that nations that share a language are most likely to develop asymmetrical attitudes towards each other. This situation occurs, for instance, when there are linguistic similarities between a small and a larger neighbouring nation. Examples are Austrians versus Germans, Canadians versus Americans, Montenegrins versus Serbs, and Frenchspeaking Belgians versus French. In this special situation social identity theory leads to predictions that are in sharp contrast with cognitive balance models. According to the similarity-attraction principle, there should be more amicability due to the shared linguistic background. According to social identity theory, however, smaller nations find themselves in a position, in which their social identity is even more under threat. Therefore, smaller nations have even more reason to judge a linguistically resembling, larger nation, less positively. Being linguistically similar or comparable the larger fellow nation forms an inevitable social comparison partner for them, but being smaller, and consequently less powerful, they find it more difficult to obtain positive distinctiveness. Because of the linguistic similarity, the superiority of the other nation becomes more salient. Consequently, the smaller nations may react against the larger nations by showing ingroup favouritism and outgroup derogation. In particular, in order to maintain their identity they will not easily acknowledge the more successful comparison partner's superiority, which would be a blow to their social identity, but will perceive that comparison partner's superiority instead as arrogance. Arrogance can be characterised as 'insolent pride' which can easily occur in situations in which one interacts with others who are more or less similar but are able to exert more power. We therefore predict: Small nations will perceive larger, but linguistically similar nations as less sympathetic and more arrogant than they are seen by these larger nations (Hypothesis 3).

Groups that discover themselves to be similar to each other should be especially motivated to show inter-group differentiation (Brown \& Abrams, 1986; Brown, 2000). An additional way to reduce the threat to one's identity is to deny or degrade the similarity with the potential source of the threat. Social identity theory is not the only theory to claim that people seek for distinctiveness from others. For example, Snyder \& Fromkin (1980) have stressed the human search for distinctiveness and so has 
Brewer (1991) in her optimal distinctiveness theory. Social identity theory, however, has stressed the motivational function this phenomenon may have to protect one's self-esteem. By reducing the similarity to a potentially threatening nation, social comparison with that nation becomes less compelling and consequently less threatening. Hence the fourth hypothesis: Members of smaller nations will perceive linguistically similar, larger nations as less similar to themselves than they are seen by members of these larger nations (Hypothesis 4).

There is still another way of testing the validity of a social identity theoretical approach. Social identity theory does not claim that group members will differentiate themselves positively on all dimensions. Some acknowledgement of the status of outgroups may occur when multiple dimensions are offered. Acknowledging high status to outgroups on one dimension makes it easier to perceive the own group as high on a different dimension. This identity management strategy has been called 'social co-operation' (Tajfel \& Turner, 1986; Van Knippenberg, 1989), because such an inter-group role differentiation offers some degree of positivity to the inter-group situation. Lower status groups show stronger ingroup favouritism than higher status groups on dimensions which are less related to status differences, but will show no ingroup favouritism or sometimes even outgroup favouritism on the status dimension (Ellemers \& Van Rijswijk, 1997). Research by Linssen \& Hagendoorn (1994) and Poppe \& Linssen (1999) has indeed shown that larger nations are perceived as less favourable on sociability (a non-status dimension), in particular. With respect to social comparison processes we expect that members of smaller nations will perceive themselves particularly as superior on sociability, but at the same time that they will not show such an ingroup bias on 'economic competence', a statusrelevant dimension. We assume that sociability will be more highly appreciated than economic competence. This distinction between a morality/sociability and competence dimension (e.g. Phalet \& Poppe, 1997) or between a warmth and competence dimension (e.g. Fiske, 2000) is well established in the literature. In view of the small differences in socio-economic situations of the nations involved in this study and the relatively objective criteria of economic success, there is not much room for exaggerated attributions of differences in economic competence. Yet, we expect that, particularly, between more obvious comparison partners such as linguistically similar nations, distortions will occur. Hence our last two hypotheses: members of smaller nations will perceive linguistically similar, larger nations as economically more competent than they are seen by these larger nations (Hypothesis 5a), but: members of smaller nations will perceive linguistically similar, larger nations as less sociable than they are seen by these larger nations (Hypothesis $5 \mathrm{~b}$ ).

\section{THE EUROPEAN UNION AS A SOCIAL PSYCHOLOGICAL LABORATORY}

Although many ingroup identifications have been successfully manipulated in the laboratory, it would be impossible to manipulate such a historically and culturally developed entity as the national group. Fortunately Europe, more than any other continent, offers a rich variety of nations which differ on relevant dimensions such as size, and degree of linguistic similarity. In order to test the asymmetry effects with respect to linguistic similarity in interaction with country size, respondents from France, Belgium (both Dutch- and French-speaking respondents), The Netherlands, and Germany were included in this study. The geographical distance between these nations is very small in all four cases. In fact they are all neighbouring countries with exception of France and the Netherlands, which are only a one to two hours' drive apart. Moreover, they form interesting groups, because they offer among each other various levels of linguistic variety. Belgium, in particular, presents the crucial 'experimental' conditions to test the asymmetry hypotheses, because it consists of two important linguistic groups. On the one side the Walloons (French-speaking Belgians) who share their language 
with the French (the larger nation), on the other side the Flemish who share their language with the Dutch, so that linguistic (dis)similarity with other nations varies within one nation. In addition, Belgium offers an interesting 'experimental' condition, because it borders on two large nations: France and Germany. France is linguistically similar to the Walloons, but different from the Flemish. Germany is linguistically different from the Walloons but - although not similar-somewhat related to the Flemish, so that the effect of linguistic relatedness ${ }^{1}$ can be examined in addition to that of linguistic similarity.

The Flemish-Dutch relationships form an ideal case to test the social identity predictions even more purely. Although Belgium and The Netherlands hardly differ with respect to country size, population size, and political power, the Dutch are linguistically dominant with respect to the Flemish because they outnumber the Dutch-speaking Belgians by a ratio of 16:6. On the basis of the similarities with respect to language and country size, there would be many reasons to expect positive reciprocal relationships. In contrast, according to social identity theory Dutch-speaking Belgians would show the same reactions towards the Dutch as the French-speaking Belgians towards the French. This means that they would feel threatened and consequently feel less sympathy towards the Dutch than vice versa, attribute more arrogance to them, judge the similarity between the two nations as lower than vice versa, and show a reverse reaction with respect to economic competence.

Belgium, France, Germany, and The Netherlands are used as target nations to test the asymmetry predictions. In order to test the predictions concerning the effects of size the same four nations are used as target nations, but two cases are added to make the sample of target nations somewhat broader: one small (Denmark) and one large nation (Great Britain). Both nations are linguistically different from the four other nations, so that judgements with respect to these nations may not be influenced by linguistic similarity. No respondents from these countries participated. Thus this study deals with six, geographically close target nations with highly comparable political and socioeconomic conditions, so political systems or socio-economic status may not substantially influence that attitudes. The six nations differ, however, strongly with respect to country and population size. The three large countries are Germany (population: 82.1 million; area: 357,000 $\mathrm{km}^{2}$ ), France (population: 59.4 million; area: 547,000 $\mathrm{km}^{2}$ ), and Great Britain (population: 59.3 million; area: $244,800 \mathrm{~km}^{2}$ ). The smaller nations are The Netherlands (population: 16 million; area: $41,500 \mathrm{~km}^{2}$ ), Belgium (population 10.2 million; area: $30,500 \mathrm{~km}^{2}$ ), and Denmark (population: 5.3 million; 43,100 $\mathrm{km}^{2}$ ). Respondents (comparable from nation to nation with respect to age and education) from two small and two large nations will judge three large nations and three small nations, so that Hypotheses 1 and 2 can be tested. Great Britain and Denmark are only included as target nations to test the first two hypotheses.

\section{METHOD}

\section{Participants}

Four hundred and five social science students from French-speaking Belgium (113), Dutch-speaking Belgium (66), France (68), Germany (72), and The Netherlands (86) took part in the study. Fifty-six per cent were female, $43 \%$ were male students. Forty-nine per cent of these students studied

\footnotetext{
${ }^{1}$ Although Dutch and German are different languages, they are related. When the Dutch went their way politically, their from of lower Franconian became a separate language, in contrast to other forms which have become known as dialects of German (Schmidt, 1993).
} 
economics or management; $46 \%$ were psychology students, $5 \%$ came from other disciplines. The average age was 21.9 years $(\mathrm{SD}=3.35)$ with negligible age differences from country to country.

\section{Instruments}

Scores on sympathy for all six nations (including the respondents' own nation) were obtained by having the respondent assign a number of points according to the degree in which the nations were disliked or liked $(0=$ extreme disliking; $50=$ neither liking nor disliking; $100=$ extreme liking $)$. The scale is transformed into a 10-point scale.

Similarity was measured by asking: 'In what measure do you think that the inhabitants of the country concerned resemble the people of your own country?' ( $1=$ absolutely not; $5=$ very much).

To measure the other variables a list of 19 descriptions was used, consisting of positive and negative traits, many of which had been used earlier to describe European nations (Buchanan \& Cantrill, 1972). Respondents were asked to indicate the percentages of people from their own and the five other countries that possessed the traits indicated (Hewstone, 1986). The percentages were transformed into a 10-point scale, from $1(<10 \%)$ to $10(100 \%)$. Next, they indicated on a 7-point scale how bad or good the 19 traits were in their eyes. Factor analyses on these traits carried out for each target nation yielded in all cases the same two factors explaining between $31 \%$ and $35 \%$ of the variance, depending on the nation. On the first factor, with Eigen values of over 3, the items 'tolerant', 'pleasant', 'easygoing', 'friendly', and 'having a sense of humour' had high factor loadings. These five traits, from the list of 19 traits, were selected to form the sociability scale. Cronbach's alphas for this scale varied between 0.80 and 0.84 across target nations. Means on the sociability scale were moderately to highly correlated with the sympathy scores, ranging from $r=0.43$ if the Danes were the target to $r=0.63$ if the British were the target. On the second factor, with Eigenvalues of over 2.5, the items 'practical', 'money-oriented', 'business-like', 'down-to-earth', and 'progressive' had high factor loadings. These five items formed the economic competence scale. Cronbach's alphas for this scale varied from 0.69 to 0.80 across target groups. The two factors resemble to a large extent the factors 'morality/sociability' and 'economic power' factors found in Poppe and Linssen's (1999) study. The five items forming the sociability scale had an average positivity rating of 6.18 on a 7-point scale, whereas the five items forming the economic competence had an average positivity rating of 5.11 on the same scale. In other words, as expected, sociability was more highly appreciated than economic competence although the latter was also rated quite positively. Arrogance was measured by one single item with a very low positivity rating of 1.98 . It was not related to sociability and economic competence, but emerged as a third factor out of the factor analyses together with the traits cruel and domineering.

Degree of contact was measured by two questions with respect to five of the six target nations; the respondents' own country was not included. The two questions were: 'How often have you been in the country concerned?' $(1=$ never; $4=$ five times or more $)$; and 'For how long have you been in the country concerned?' $(1=$ never; $6=$ longer than one year). The scores on the two questions were combined into an average score because they were highly correlated; for all countries a correlation of over 0.80 was found.

Finally, some biographical data on gender, age, nationality, and academic career were collected, as well as some information concerning degree of knowledge about other nations and interest in other nations.

\section{Procedure}

The study was presented as a collaborative effort of three European universities (from France, Germany, and The Netherlands) to investigate 'what people know, think, and feel about the European Union'. The 
questionnaire 'Opinion study on the fifteen member states of the European Union' was filled out on a voluntary basis in (small) groups. The instructions said: 'The questionnaire would be too long if we asked your opinion about all the countries of the EU. Therefore, we varied the questionnaires such that you will only be asked about five countries.' In each country a local staff member gave the instructions, in order to avoid that politeness towards a researcher from another country would influence attitudes towards that country. The respondents received, dependent on the country, the questionnaire in German, Dutch or French. The questionnaires had been translated from English by the team of multilingual researchers. The questionnaire started with neutral questions on knowledge with respect to five other countries, number and duration of visits spent in other countries, and willingness to live in the five countries. Next, there were some questions about the degree of interest in other countries and about the similarity to one's own country. Finally, respondents filled out the questions with respect to sympathy and traits. It took the respondents approximately 15 to 20 minutes to fill out the questionnaire. In general, they were quite willing to participate in the study.

\section{RESULTS}

The participants did not answer every question so that the sample sizes may vary depending on the variable involved in the analysis. As a consequence there may be slight differences in the means presented in the tables and in the text. Questions with respect to Denmark, in particular, were frequently skipped probably because Denmark was the least-known country. Therefore, analyses involving Denmark as a target nation (only concerning the first two hypotheses) have a reduced number of degrees of freedom. Most analyses are ANOVAs; the reported $p$-values corresponding with the $F$-values are always two-tailed. In a two-group or two-condition comparison significance at the 0.10 level in a two-tailed test corresponds to significance at 0.05 in a one-tailed test. Therefore, where results are in the direction as predicted, $p$-values between 0.05 and 0.10 are also mentioned.

\section{Country Size and Sympathy Ratings}

The first two predictions concerned the effects of the country size on sympathy ratings (see Table 1). Hypothesis 1 stated that members of smaller nations (Belgium and The Netherlands) would see larger

Table 1. Mean sympathy scores for small, large nations, own nation, and similar size nations, except own nation $(1=$ extremely low; $10=$ extremely high). Respondents from four nations

\begin{tabular}{|c|c|c|c|c|c|}
\hline Respondents & Small nations & Large nations & $F(\mathrm{df})$ & Own nation & $\begin{array}{l}\text { Similar size } \\
\text { (except own) }\end{array}$ \\
\hline \multicolumn{6}{|l|}{ Small nations } \\
\hline Dutch & $\begin{array}{c}7.26 \\
(0.78)\end{array}$ & $\begin{array}{c}6.34 \\
(0.99)\end{array}$ & $\begin{array}{l}34.24 * * * \\
(1.58)\end{array}$ & $\begin{array}{c}7.46 \\
(1.23)\end{array}$ & $\begin{array}{c}7.15 \\
(0.84)\end{array}$ \\
\hline Belgians & $\begin{array}{c}6.78 \\
(1.01)\end{array}$ & $\begin{array}{l}6.05 \\
(0.95)\end{array}$ & $\begin{array}{l}39.48 * * * \\
(1.60)\end{array}$ & $\begin{array}{c}7.11 \\
(1.36)\end{array}$ & $\begin{array}{l}6.65 \\
(1.02)\end{array}$ \\
\hline \multicolumn{6}{|c|}{ Large nations } \\
\hline French & $\begin{array}{c}6.68 \\
(1.06)\end{array}$ & $\begin{array}{c}6.07 \\
(1.15)\end{array}$ & $\begin{array}{c}4.17 * \\
(1.23)\end{array}$ & $\begin{array}{c}6.48 \\
(1.47)\end{array}$ & $\begin{array}{c}5.85 \\
(1.17)\end{array}$ \\
\hline Germans & $\begin{array}{c}7.05 \\
(1.38)\end{array}$ & $\begin{array}{c}6.67 \\
(1.31)\end{array}$ & $\begin{array}{c}4.26^{*} \\
(1.24)\end{array}$ & $\begin{array}{c}5.76 \\
(1.35)\end{array}$ & $\begin{array}{c}6.65 \\
(1.30)\end{array}$ \\
\hline
\end{tabular}

Note: $*=p<0.05 ; * * *=p<0.001$. 
nations (Germany, Great Britain and France) as less sympathetic as compared to smaller nations (The Netherlands, Belgium, and Denmark), while larger nations (France and Germany) would not show an in-group bias towards large nations. A MANOVA with size of respondents' country (large versus small) as between-subjects factor and size of target nation (large versus small) as within-subjects factor was carried out to test the hypothesis. A significant main effect of target nations on sympathy ratings was found, $F(1,167)=48.92, p<0.001$, which means that smaller nations received higher sympathy ratings than larger nations, $M=7.01$ versus $M=6.19$. No main effect of respondents' nation size was found. In addition we found a weak interaction effect, $F(1,167)=3.21, p<0.10$, which means that members of the two small nations had a more outspoken preference for smaller nations than members of the larger nations. In line with Hypothesis 1, members of larger nations did not show any bias towards large nations; on the contrary, they rated the smaller nations instead as more sympathetic, $M=6.86$ versus $M=6.37, F(1,48)=8.10 ; p<0.01$.

In Hypothesis 2 we predicted that members of small nations would judge their own nation, in particular, as more sympathetic. This appears indeed to be the case for the Dutch and Belgians sympathy ratings. The Dutch and Belgians rated their own nation as even more sympathetic than they rated the other two small nations, $M=7.46$ versus $7.15 ; F(1,58)=3.86 ; p<0.10$, for the Dutch and $M=7.11$ versus $6.65 ; F(1,64)=5.07 ; p<0.05$, for the Belgians. As mentioned above, questions with respect to Denmark were frequently skipped resulting in a reduced number of degrees of freedom. However, when Denmark is excluded from the analysis as target nation, differences in ratings of the own and the other small nation remain significant in accordance with the predictions. The larger nations show a different pattern. The French do not rate themselves as higher than they rate smaller nations, but they do rate themselves as more sympathetic in comparison to the other two large nations, $M=6.48$ versus $5.85 ; F(1,57)=7.88 ; p<0.001$. Interestingly, the Germans do not show any ingroup bias at all: they even rate their own nation as significantly less sympathetic than they rate other large nations, $M=5.76$ versus $6.65 ; F(1,63)=26.38 ; p<0.001$. The results support Hypothesis 2.

\section{Country Size and Linguistic Similarity}

The subsequent hypotheses concerned the asymmetry effects of country size in combination with linguistic similarity. ANOVAs with size of respondents' country (large versus small) as betweensubjects factor and mutual sympathy and arrogance ratings as dependent variables, were carried out to test the hypotheses. In Hypothesis 3, we stated that respondents from smaller nations would perceive their linguistically similar but larger neighbours as less sympathetic and more arrogant than these nations would see the smaller nations (see Tables 2 and 3). French-speaking Belgians perceive the French indeed as significantly less sympathetic, than the French see the Belgians, $M=6.11$ versus $6.58, F(1,168)=3.45, p<0.10$. Remarkably, Dutch-speaking Belgians perceive the French as more sympathetic than do French-speaking Belgians, $M=6.57$ versus $6.11 ; F(1,172)=3.39 ; p<0.10$. Also, as predicted, Dutch-speaking Belgians perceive the Dutch as significantly less sympathetic than the Dutch see the Belgians, $M=6.40$ versus $7.01, F(1,145)=6.94, p<0.01$. With respect to arrogance ratings the pattern was even more convincing. French-speaking Belgians perceive the French as considerably more arrogant, than the French see the Belgians, $M=6.98$ versus 3.81, $F(1,170)=100.78, p<0.001$. Remarkably, Dutch-speaking Belgians perceive the French as less arrogant than do French-speaking Belgians, $M=6.36$ versus $6.98 ; F(1,166)=3.46 ; p<0.10$. Also in line with prediction, Dutch-speaking Belgians perceive the Dutch as considerably more arrogant than the Dutch see the Belgians, $M=6.42$ versus 3.71, $F(1,293)=56.15, p<0.001$. Interestingly, contrary to Dutch-speaking Belgians, French-speaking Belgians perceive the Dutch as much less arrogant, 
Table 2. Mean sympathy scores for four target nations ( $1=$ extremely low; $10=$ extremely high). Asymmetrical relations between linguistically similar nations are in bold type

\begin{tabular}{lcccc}
\hline $\begin{array}{l}\text { Target nations: } \\
\text { respondents: }\end{array}$ & Dutch & Belgian & French & German \\
\hline Dutch $(N=86)$ & 7.58 & $\mathbf{7 . 0 1}$ & 5.88 & 5.91 \\
& $(1.23)$ & $(1.20)$ & $(1.73)$ & $(1.56)$ \\
Dutch-speaking & $\mathbf{6 . 4 0}$ & 7.64 & 6.57 & 5.87 \\
Belgians $(N=66)$ & $(1.62)$ & $(1.34)$ & $(1.21)$ & $(1.58)$ \\
French $(N=68)$ & 7.05 & $\mathbf{6 . 5 8}$ & 6.46 & 5.93 \\
& $(1.39)$ & $(1.39)$ & $(1.47)$ & $(1.67)$ \\
French-speaking & 6.45 & 7.19 & $\mathbf{6 . 1 1}$ & 5.65 \\
Belgians $(N=113)$ & $(1.41)$ & $(1.36)$ & $(1.72)$ & $(1.57)$ \\
Germans $(N=72)$ & 7.27 & 6.76 & 6.55 & 5.74 \\
& $(1.41)$ & $(1.40)$ & $(1.78)$ & $(1.35)$ \\
Total $(N=405)$ & 6.92 & $(1.34)$ & 6.27 & $(1.51$ \\
& $(1.48)$ & & $(1.64)$ & \\
& & & &
\end{tabular}

Table 3. Mean 'perceived arrogance' scores for four target nations ( $1=$ extremely low; $10=$ extremely high). Asymmetrical relations between linguistically similar nations are in bold type

\begin{tabular}{lcccc}
\hline $\begin{array}{l}\text { Target nations: } \\
\text { respondents: }\end{array}$ & $\begin{array}{c}\text { Dutch } \\
\text { 'arrogance' }\end{array}$ & $\begin{array}{c}\text { Belgian } \\
\text { 'arrogance' }\end{array}$ & $\begin{array}{c}\text { French } \\
\text { 'arrogance' }\end{array}$ & $\begin{array}{c}\text { German } \\
\text { 'arrogance' }\end{array}$ \\
\hline Dutch $(N=86)$ & 6.13 & $\mathbf{3 . 7 1}$ & 7.16 & 6.92 \\
& $(1.74)$ & $(1.97)$ & $(2.06)$ & $(1.90)$ \\
Dutch-speaking & $\mathbf{6 . 4 2}$ & 4.34 & 6.36 & 6.27 \\
Belgians $(N=66)$ & $(2.37)$ & $(1.64)$ & $(2.11)$ & $(1.89)$ \\
French $(\mathrm{N}=68)$ & 3.83 & $\mathbf{3 . 8 1}$ & 5.69 & 5.11 \\
& $(1.96)$ & $(1.87)$ & $(2.08)$ & $(2.29)$ \\
French-speaking & 4.51 & 4.38 & $\mathbf{6 . 9 8}$ & 5.55 \\
Belgians $(N=113)$ & $(1.80)$ & $(1.71)$ & $(2.07)$ & $(1.89)$ \\
Germans $(N=72)$ & 4.23 & 4.12 & 6.25 & 6.22 \\
& $(2.18)$ & $(1.58)$ & $(2.29)$ & $(2.20)$ \\
Total $(N=405)$ & 5.02 & 4.09 & 6.58 & 6.00 \\
& $(2.21)$ & $(1.78)$ & $(2.17)$ & $(2.11)$ \\
\hline
\end{tabular}

$M=4.51$ versus 6.42: $F(1,167)=34.32 ; p<0.001$. Altogether results clearly support Hypotheses 2 and 3 concerning the effects of linguistic similarity.

A theoretical important question is whether a similar pattern would be found when we look at linguistic relatedness. For that purpose we focus again on Dutch- and French-speaking Belgians, but now in relation with Germans. Dutch-speaking Belgians indeed see Germans as less sympathetic than Germans perceive the Belgians, $M=5.87$ versus $M=6.76, F(1,92)=7.31, p<0.01$. Dutch-speaking Belgians see Germans as more arrogant as well than Germans perceive the Belgians, $M=6.27$ versus $M=4.12, F(1,122)=47.56, p<0.001$. Interestingly, French-speaking Belgians do rate the Germans as less arrogant than do Dutch-speaking Belgians, $M=5.55$ versus $M=6.27, F(1,167)=5.54$, $p<0.05$. The Dutch, who are comparable to the Dutch-speaking Belgians with respect to linguistic relatedness to the Germans, show the same pattern. The Dutch too see Germans as less sympathetic, $M=5.91$ versus $M=7.27, F(1,141)=28.56, p<0.001$, and as more arrogant, $M=6.92$ versus $M=4.23, F(1,148)=65.07, p<0.001$, than Germans perceive the Dutch.

Next, we tested our prediction concerning the asymmetry in perceived similarity between countries that are linguistically similar, but different in size (Hypothesis 4). French indeed judged Belgians as 
more similar to themselves, $M=3.27$, than French-speaking Belgians the French, $M=2.93$, $F(1,168)=5.08, p<0.05$. The results between Dutch and Dutch-speaking Belgians show the same pattern. Dutch rated Belgians as more similar to themselves, $M=2.77$ than Dutch-speaking Belgians did with respect to the Dutch, $M=2.26, F(1,149)=10.09, p<0.01$. Remarkably, French-speaking Belgians rated the Dutch as more similar to themselves than did the Dutch-speaking Belgians, $M=2.67$ versus $M=2.26, F(1,163)=6.39, p<0.05$. In addition, Germans indeed judged Belgians as more similar to themselves, $M=2.98$, than Dutch-speaking Belgians the-linguistically relatedGermans, $M=2.25, F(1,168)=5.08, p<0.05$. Even though differences were not significant, the same pattern was found between Germans and Dutch (German similarity ratings of the Dutch were $M=2.92$ versus $M=2.72$ for Dutch similarity ratings of the Germans). In conclusion, our results support the fourth hypothesis.

The fifth hypothesis predicted that smaller nations would perceive larger linguistically similar or related nations as economically more competent than vice versa, but would show a reverse pattern with respect to sociability ratings. French-speaking Belgians rate the economic competence of the French indeed as higher than the French rate Belgian economic competence, $M=6.16$ versus 5.24, $F(1,161)=28.06, p<0.001$. With respect to sociability the expected reverse pattern was found: French-speaking Belgians rate French as less sociable than the French rate the Belgians, $M=5.63$ versus $6.15, F(1,168)=5.55, p<0.05$. Dutch-speaking Belgians do not differ from French-speaking Belgians in their ratings of French economic competence, but they do perceive the French as more sociable than do the French-speaking Belgians, $M=6.03$ versus $M=5.63, F(1,166)=3.65, p<0.10$. In line with the predictions, Dutch-speaking Belgians rated Dutch economic competence as higher than vice versa, $M=6.95$ versus $M=4.92, F(1,139)=80.51, p<0.001$. With respect to sociability, however, no significant differences were found. French-speaking Belgians rate Dutch economic competence lower than Dutch-speaking Belgians, $M=6.56$ versus $M=6.95, F(1,160)=5.57$, $p<0.05$. Dutch-speaking Belgians rated German economic competence as higher, $M=6.98$ versus $6.02, F(1,117)=23.44, p<0.001$, and German sociability as lower, $M=5.33$ versus 6.19 , $F(1,121)=13.64, p<0.001$ than vice versa. In these reactions, however, they did not differ from French-speaking Belgians. The Dutch also rated German economic competence as higher, $M=7.10$ versus $6.31 ; F(1,117)=23.44, p<0.001$, and German sociability as lower, $M=5.47$ versus 7.00 , $F(1,152)=50.18, p<0.001$, than vice versa. All together Hypotheses 5a and 5b were supported to a large extent. Although the small nations acknowledge the economic competence of larger linguistically similar nations than vice versa, this does not mean that they attribute lower economic competence to themselves. French-speaking Belgians rate themselves and the French as equally high on economic competence, and Dutch-speaking Belgians rate themselves as equally high as they rate the Dutch and the Germans. The Dutch rate themselves even higher on economic competence than they rate the Germans, $M=7.44$ versus $7.09, F(1,83)=10.07, p<0.01$.

\section{Further Analyses}

Finally, we checked whether perceived similarity and level of contact would be related to sympathy towards other nations. As Table 4 shows, in 13 of the 25 cases, significant, positive relations were found between perceived similarity to and sympathy towards a nation. Thus, results offer some support for the similarity-attraction hypothesis. With respect to the contact-hypothesis results are less supportive. In 8 of the 25 cases significant, positive relations were found. All correlations are low (see Table 5). Stepwise regression analyses were carried out for each nationality of the respondents with perceived similarity and degree of contact as predictors and sympathy towards other nations as dependent variable. The variables contact and perceived similarity were almost orthogonal. 
Table 4. Correlations between similarity and sympathy scores with respect to six nations. Respondents from four countries

\begin{tabular}{llcccc}
\hline & \multicolumn{3}{c}{ Respondents } \\
\cline { 2 - 5 } & $\begin{array}{c}\text { Dutch } \\
(N=86)\end{array}$ & $\begin{array}{c}\text { French } \\
(N=68)\end{array}$ & $\begin{array}{c}\text { Germans } \\
(N=72)\end{array}$ & $\begin{array}{c}\text { Dutch-speaking } \\
\text { Belgians } \\
(N=66)\end{array}$ & $\begin{array}{c}\text { French-speaking } \\
\text { Belgians } \\
(N=113)\end{array}$ \\
\hline $\begin{array}{l}\text { Target nations } \\
\text { Germany }\end{array}$ & $0.36^{* *}$ & $0.38^{* *}$ & - & $0.59 * *$ & $0.38^{* *}$ \\
$\begin{array}{l}\text { Denmark } \\
\text { Belgium }\end{array}$ & $0.44^{* *}$ & -0.31 & -0.22 & 0.36 & 0.26 \\
$\begin{array}{l}\text { Netherlands } \\
\text { France }\end{array}$ & $0.25^{*}$ & 0.22 & -0.03 & - & $0.32 * *$ \\
Great Britain & - & -0.21 & -0.02 & $0.32 * *$ & 0.14 \\
\hline
\end{tabular}

Significance (one-tailed): $*=p<0.05 ; * *=p<0.01$.

Table 5. Correlations between contact and sympathy scores with respect to six nations. Respondents from four countries

\begin{tabular}{llllcc}
\hline & \multicolumn{3}{c}{ Respondents } \\
\cline { 2 - 5 } & $\begin{array}{c}\text { Dutch } \\
(N=86)\end{array}$ & $\begin{array}{c}\text { French } \\
(N=68)\end{array}$ & $\begin{array}{c}\text { Germans } \\
(N=72)\end{array}$ & $\begin{array}{c}\text { Dutch-speaking } \\
\text { Belgians } \\
(N=66)\end{array}$ & $\begin{array}{c}\text { French-speaking } \\
\text { Belgians } \\
(N=113)\end{array}$ \\
\hline $\begin{array}{l}\text { Target nations } \\
\text { Germany }\end{array}$ & 0.08 & $0.32^{* *}$ & - & 0.17 & 0.17 \\
$\begin{array}{l}\text { Denmark } \\
\text { Belgium }\end{array}$ & 0.15 & 0.20 & 0.12 & 0.01 & -17 \\
Netherlands & 0.02 & $0.26^{*}$ & 0.01 & -0.06 & -0.04 \\
$\begin{array}{l}\text { France } \\
\text { Great-Britain }\end{array}$ & - & 0.26 & 0.12 & 0.01 & $0.20^{*}$ \\
\hline
\end{tabular}

Significance (one-tailed): $*=p<0.05 * *=p<0.01$.

Correlations between the two variables varied between $r=-0.33$ and $r=+0.33$. Only in 5 of the 25 cases did level of contact significantly add explained variance to perceived similarity as predictor for sympathy. Significant additional explained variance was found in the following cases: French contacting Germans, $R^{2}=0.09, F(1,55)=6.19, p<0.05$; Dutch contacting British, $R^{2}=0.08$, $F(1,75)=7.16, p<0.01$; French-speaking Belgians contacting British, $R^{2}=0.07, F(1,88)=6.90$, $p<0.01$; Dutch contacting French, $R^{2}=0.10, F(1,80)=10.32, p<0.01$; and French-speaking Belgians contacting French, $R^{2}=0.03, F(1,103)=3.94, p<0.05$. When sociability was taken as dependent variable, contact did in none of the cases have any additional predictive value. Altogether results hardly support the contact hypothesis.

\section{DISCUSSION}

In this study we focused on asymmetrical attitudes between small and large nations. We assumed that asymmetrical attitudes originate from differential threats to national social identities. Social identity theory appears to be particularly suitable for explaining asymmetrical attitudes, because it states that 
nations, like all groups, strive for positive distinctiveness. For smaller nations it is difficult to acquire positive distinctiveness, in particular, when they are compared to larger nations with a similar or related language. Consequently, in order to maintain or protect their social identity they exhibit protective psychological reactions. Results clearly support a social identity theory explanation.

Our first predictions were related to the effects of country size. Departing from the idea that smaller nations' social identity would be threatened by larger nations, we predicted that smaller nations would find larger nations less sympathetic than smaller nations whereas larger nations would not show such a bias. Results confirmed that members of smaller nations (Belgium and The Netherlands) perceived the larger nations, France, Germany and Great Britain, as less sympathetic than the smaller nations, Belgium, Denmark, and The Netherlands. As predicted, the larger nations did not show any ingroup bias. Although the results are in line with social identity theory, they might also be accounted for by real historical conflicts. Indeed, the larger nations have been involved in aggressive acts against the smaller nations. For instance, France actually occupied Belgium and The Netherlands in the early nineteenth century, and Germany invaded Belgium and The Netherlands in the last century. The French occupation of Belgium, however, cannot explain why Dutch-speaking Belgians have more positive attitudes towards the French than do the French-speaking Belgians, neither can the German occupation of Belgium explain why French-speaking Belgians perceive the Germans as less arrogant than do Dutch-speaking Belgians. Social psychological mechanisms may offer a better explanation of international attitudes than historical events. In 1999 The Economist published an interesting article with respect to historical explanations of international attitudes ('Britain and the war'). It mentioned that in spite of the British obsession with the war-British TV channels weekly schedule several Second World War dramas - opinion polls find little dislike of Germany.

Theories referring to real historic conflicts cannot explain why small nations would judge themselves more positively than they would judge other small nations. Therefore, a purer test of social identity theory is the prediction that respondents from smaller nations - in their search for a positive social identity - would show such an ingroup bias. This is indeed what happened. Belgians and Dutch perceived themselves as more sympathetic than they saw other small nations. Because larger nations experience less threat to their social identity, there is no reason to expect such a bias for them, and that is what we found. Instead they rated larger nations as less sympathetic than they rated smaller nations. Whereas the Germans perceive themselves as less sympathetic than they perceive the other large nations, the French do the opposite: they rate themselves as more sympathetic than they rate the Germans and British. The French ingroup bias might also derive from a perceived threat to their national identity. They are linguistically overshadowed by the predominance of English in Europe, on the one hand, and economically by Germany, on the other.

Our second set of predictions referred to the effects of country size in combination with degree of linguistic resemblance. We contended that larger nations that are linguistically similar are particularly threatening to smaller nations because these nations, being linguistically similar, cannot easily escape from social comparisons with the larger nations. As a consequence they would show reactions to protect their social identity against those larger, linguistically resembling nations. These reactions consist of perceiving those nations as less sympathetic, of attributing arrogance to them, and of perceiving them as less similar to their own nation. As predicted, French-speaking Belgians described the French as less sympathetic and more arrogant than vice versa. They also perceived the French as less similar than the French perceive the Belgians. The same holds with respect to Dutch-speaking Belgians and - the linguistically related-Germans. The same pattern was also found with respect to the Dutch-German relationship. Whereas the smaller nations attributed arrogance to larger nations, these nations (France and Germany) did not show any sign of such arrogance. They rather showed modesty by describing themselves as not more sympathetic, sociable, and economically competent than other nations describe them. 
Acknowledging high status to outgroups on one dimension makes it easier to perceive the own group as high on a different dimension. Within this so-called 'social cooperation' strategy to maintain one's self-esteem people tend to show ingroup bias on the moral dimension, in particular. Hence our prediction that smaller nations would acknowledge high status in economic competence to the nation that threatens their identity, but low status in sociability. French-speaking Belgians indeed rated the economic competence of the French higher and their sociability lower than vice versa. The same pattern was found between the Dutch-speaking Belgians and the Germans, and between the Dutch and the Germans. Apparently it is more important — and easier - for the smaller nations to rate themselves high on the 'warm-cold' dimension (Fiske, 2000) than on an-emotionally-more neutral and less ambiguous competence dimension.

The most interesting and convincing test of social identity theory offers the Belgian-Dutch comparison. Belgium and The Netherlands are quite comparable in country size, population, and economic and political power. Moreover they have had relatively friendly relations for 170 years. The 6 million Dutch-speaking Belgians, however, form linguistically a minority as compared to the 16 million Dutch. Being similar to the Dutch in so many respects, the Dutch-speaking Belgians will experience enhanced threat to their identity and consequently do their best to positively distinguish themselves from the Dutch, whereas the French-speaking Belgians would have less reasons to 'distance' themselves from the Dutch. Results support this supposition: Dutch-speaking Belgians perceived the Dutch as less sympathetic and attributed much more arrogance to the Dutch than the Dutch did towards the Belgians, while French-speaking Belgians did not perceive the Dutch as arrogant. Dutch-speaking Belgians also perceived themselves as less similar to the Dutch than vice versa and-remarkably - even less than the French-speaking Belgians did. Also in line with the 'social cooperation' prediction Dutch-speaking Belgians rated the economic competence of the Dutch as higher than vice versa, and, interestingly again, as higher than did the French-speaking Belgians.

The relationships between the Flemish and the Dutch, and the French-speaking Belgians and the French, suggest that a common language is not only a factor of similarity, but also a source of differentiation. The common language not only makes it possible to get informed about differences that otherwise would go unnoticed. The common language itself also presents subtle differences between nations, such as accents and idiomatic expressions that are highly valued by the speakers of the language (see, for instance, Bourhis, Giles, Leyens, \& Tajfel, 1979). However, French as spoken in France (around Paris, in particular), and Dutch as spoken in the Western part of The Netherlands are normative. As a consequence Belgian French and Belgian Dutch are seen as 'picturesque' by many French and Dutch, respectively. This may explain why the French-speaking Belgians perceived the French, and the Flemish the Dutch as arrogant.

In the Introduction we referred to the similarity-attraction hypothesis and the contact hypothesis as psychological principles that might account for differences in attitudes towards other nations. At the country level these theories had no explanatory value at all: for instance, French like the Danes and the Dutch, but these nations were perceived as most dissimilar to the French and least visited by them. When we look at the data at the individual level results supported to some extent the idea that similarity leads to attraction. In half of the cases significantly positive relationships were found between sympathy and perceived similarity. In those cases respondents liked other nations more when they are perceived as similar to themselves. However, the relationships are relatively weak. It would seem likely that people visit countries they are in favour of. Nevertheless contact did not have any significant impact in the majority of the cases. Only in 5 out of 25 cases did contact as a predictor of sympathy have additional explained variance to perceived similarity. In all cases this occurred in relation to larger nations. Probably, because people generally start with less positive attitudes towards larger nations, there is more room to make a shift in the positive direction as a consequence of contact. Altogether contact did not have a substantial impact on sympathy ratings. This result is not an isolated 
finding of the present study. It has repeatedly been found among student populations (e.g. Klineberg \& Hull, 1979; Stroebe, Lenkert \& Jonas, 1988).

The scope of this study has been limited in several aspects. Only four nations participated, respondents were restricted to student populations of their respective countries, and the study has only been a momentary registration of attitudes. Future research should include more diverse samples, more nations, and ideally have a longitudinal character so that the impact of 'historic events' on attitudes can be examined.

An important final question is: What can be done to improve attitudes toward other nations when we look at the results of this study? Enhancing contact between nations does not seem to be a great contribution to improving international understanding, although-fortunately-it seems to have some positive effect on the attitudes towards larger nations. Because the results clearly supported social identity theory, this theory should offer suggestions for improving international attitudes. One obvious aim would be to create a superordinate or common group, such as 'We are all Europeans' or 'We democratic nations'. This is what The Common Ingroup Identity Model of Gaertner, Dovidio, Nier, Baker, Ward, Houlette and Loux (2000) would suggest. The model, built upon social identity theory, proposes that inter-group bias and conflict can be reduced by factors that transform participants' representations of memberships from two or more groups to one, more inclusive group. Another helpful approach could be to bring more dimensions into play and make them more salient and more valuable, so that some nations can be proud of one aspect while other nations have serious alternative dimensions they can be proud of.

\section{ACKNOWLEDGEMENTS}

The authors are grateful to Detlef Fetchenhauer, Karen van Oudenhoven, three anonymous reviewers, and Leonel Garcia-Marques for their helpful comments

\section{REFERENCES}

Allport GW. 1954. The nature of prejudice. Addison-Wesley: Cambridge MA.

Baron RA, Byrne D. 2000. Social Psychology (9th edn). Allyn and Bacon: Boston, MA.

Bar-Tal D. 1997. Formation and change of ethnic and national stereotypes: an integrative model. International Journal of Intercultural Relations 21: 491-523.

Bourhis RY, Giles H, Leyens JP, Tajfel H. 1979. Psycholinguistic distinctiveness: language divergence in Belgium. In Language and Social Psychology, Giles H, St Clair R (eds). Basil Blackwell: Oxford; 158-185.

Brewer MB. 1991. The Social Self: on being the same and different at the same time. Personality and Social Psychology Bulletin 17: 475-482.

Buchanan W, Cantrill H. 1972. How Nations See Each Other. Greenwood Press: Westport, CT.

Brown R. 2000. Social Identity Theory: past achievements, current problem and future challenges. European Journal of Social Psychology 30: 745-778.

Brown RJ, Abrams D. 1986. The effects of intergroup similarity and goal interdependence on intergroup attitudes and task performance. Journal of Experimental Social Psychology 22: 78-92.

Byrne D. 1971. The Attraction Paradigm. Academic Press: New York.

Campbell DT. 1965. Ethnocentric and other altruistic motives. In Nebraska Symposium on Motivation, Levine D (ed.). University of Nebraska Press: Lincoln, NB; 283-311.

Capozza D, Brown R (eds). 2000. Social Identity Processes. Trends in theory and research, Sage: London.

Economist. 1999. Britain and the war. 20 February, 38-39.

Edwards J. 1986. Language, Society and Identity. Basil Blackwell: Oxford. 
Ellemers N, Van Rijswijk W. 1997. Identity needs versus social opportunities: the use of group-level identity management strategies. Social Psychology Quarterly 60: 52-65.

Fiske S. 2000. Stereotyping, prejudice, and discrimination at the seam between centuries: evolution, culture, mind, and brain. European Journal of Social Psychology 30: 299-322.

Gaertner SL, Dovidio JF, Nier JA, Banker BS, Ward CM, Houlette M, Loux S. 2000. The common ingroup identity model for reducing intergroup bias: progress and challenges. In Social Identity Processes, Capozza D, Brown. R (eds). Sage: London; 133-166.

Hewstone M. 1986. Understanding Attitudes to the European Community. A social psychological study in four member states. Cambridge University Press: Cambridge.

Klineberg O, Hull WF. 1979. At a Foreign University: An international study of adaptation and coping. Praeger: New York.

Linssen H, Hagendoorn L. 1994. Social and geographical factors in the explanation of the context of European nationality stereotypes. British Journal of Social Psychology 33: 165-182.

Newcomb TD. 1961. The Acquaintance Process. Holt, Rinehart \& Winston: New York.

Pettigrew TF. 1997. Generalized intergroup contact effects on prejudice. Personality and Social Psychology Bulletin 23: 173-185.

Phalet K, Poppe E. 1997. Competence and morality dimensions of national and ethnic stereotypes: a study in six eastern-European countries. European Journal of Social Psychology 27: 703-723.

Poppe E, Linssen H. 1999. In-group favouritism and the reflection of realistic dimensions of difference between national states in Central and Eastern Europe nationality stereotypes. British Journal of Social Psychology 38: $85-102$.

Rokeach M. 1960. The Open and Closed Mind. Basic Books: New York.

Schmidt W. 1993. The nation in German history. In The National Question in Europe in Historical Context, Teich M, Porter R (eds). Cambridge University Press: Cambridge.

Sherif M. 1966. In Common Predicament: Social psychology of intergroup conflict and cooperation. Houghton Mifflin: Boston.

Sigelman L, Welch S. 1993. The contact hypothesis revisited: Black-White interaction and positive racial attitudes. Social Forces 71: 781-795.

Snyder CR, Fromkin HL. 1980. Uniquenes: The human pursuit of difference. Plenum Press: New York.

Stroebe W, Lenkert A, Jonas K. 1988. Familiarity may breed contempt. The impact of student exchange on national stereotypes and attitudes. In The Social Psychology of Intergroup Conflict: Theory, research and applications, Stroebe W, Kruglanski AW, Bar-Tal D, Hewstone M(eds). Springer: Berlin; 167-187.

Tajfel H (ed.). 1978. Differentiation Between Social Groups: Studies in the social psychology of intergroup relations. Academic Press: London.

Tajfel H, Turner JC. 1979. An integrative theory of intergroup conflict. In The Social Psychology of Intergroup Relations, Austin WG, Worchel S (eds). Brooks/Cole: Monterey, CA; 33-48.

Tajfel H, Turner JC. 1986. The social identity theory of intergroup behavior. In The Psychology of Intergroup Relations, Worchel S, Austin WG (eds). Nelson-Hall: Chicago; 7-24.

Van Knippenberg A. 1989. Strategies of identity management. In Ethnic Minorities. Social Psychological Perspectives, Van Oudenhoven JP, Willemsen TM (eds). Swets \& Zeitlinger: Amsterdam; 59-76.

Van Oudenhoven JP. 2001. Niederländer über Deutsche: Einige empirische Befunde [Dutch opinions of Germans. Some empirical data]. In Die Niederlande und Deutschland. Einander kennen und verstehen, Moldenhauer G, Vis J (eds). Waxmann Verlag: Münster; 303-312. 